\title{
CHARACTERISTICS OF GROWTH-ASSOCIATED POLYPEPTIDES IN REGENERATING TOAD RETINAL GANGLION CELL AXONS ${ }^{1}$
}

\author{
J. H. PATE SKENE ${ }^{2}$ AND MARK WILLARD ${ }^{3}$
}

Department of Anatomy and Neurobiology, Washington University School of Medicine, St. Louis, Missouri 63110

\begin{abstract}
We report here certain properties of three polypeptides that are rapidly transported in greatly increased amounts during the regeneration of toad optic nerves. All three of these growth-associated polypeptides (GAPs) are associated with a membrane(s) with a buoyant density similar to the plasma membrane. Since none of these GAPs are solubilized substantially by washing the membranes in either low or high ionic strength media, they may be "integral" membrane proteins. All three GAPs contain a significant number of polar amino acids (judging from their isoelectric points and their rapid electrophoretic migration under their native charge), suggesting that portions of each molecule must extend away from the membrane surfaces. One of these proteins (GAP-50) is a fucosylated glycoprotein. GAP-50 and GAP-43 appear to be transported preferentially to axon tips; GAP-24 may be distributed more uniformly along the axons. GAP-24 has an extremely short halflife (4 to $6 \mathrm{hr}$ ), while the maximum half-lives of GAP-43 (2 to 3 days) and GAP-50 ( 1 day) are longer. We discuss the relevance of these properties to possible roles for these polypeptides in the control of nerve regeneration.
\end{abstract}

A developing or regenerating axon engages in certain activities-such as substratum recognition, directed elongation, and filopodial movements-which might not be expected to be concerns of an axon that has already established stable synaptic connections. We recently proposed (Skene and Willard, 1981b) that such growth-specific functions may be mediated in part by a small subset of neuronal proteins (the growth-associated polypeptides (GAPs)) whose rapid axonal transport appears to be especially enhanced during the regeneration of toad retinal ganglion cells and which are barely detectable in mature retinal ganglion cells. At least two of these polypeptides (GAP-24 and GAP-43) appear to have growthassociated counterparts in the mammalian central and peripheral nervous systems (Skene and Willard, 1981c). In this communication, we report the subcellular distribution and several physical characteristics of three of the GAPs (GAP-24, GAP-43, and GAP-50, designated by

' This work was supported by Grant EYO-2682, a Jerry Lewis Neuromuscular Research Center grant, and Research Career Development Award NS00170. We thank Dr. G. R. Mintz for invaluable assistance with the ${ }^{125}$ I-lectin experiments, Dr. J. Flier for communicating unpublished results, and Dr. J. Levine, C. Baitinger, and C. Simon for helpful discussions.

'To whom correspondence may be addressed at his current address: Department of Neurobiology, Stanford University School of Medicine, Stanford, CA 94305.

${ }^{3}$ To whom correspondence should be addressed at Departments of Anatomy and Neurobiology and Biochemistry, Washington University School of Medicine, 660 South Euclid Avenue, St. Louis, MO 63110. molecular weight in kilodaltons), and consider how these properties might be related to growth-specific functions of these polypeptides.

\section{Materials and Methods}

Oplic nerves were crushed, axonally transported proteins were labeled, and polypeptides were electrophoresed as described previously (Skene and Willard, 1981b). Retinal glycoproteins were labeled by injection of 1.0 $\mathrm{mCi}$ of $\left[{ }^{3} \mathrm{H}\right]$ fucose ( 40 to $60 \mathrm{Ci} / \mathrm{mmol}$, from New England Nuclear) in $30 \mu \mathrm{l}$ of distilled $\mathrm{H}_{2} \mathrm{O}$.

Subcellular fractionation. Two toad optic nerves containing labeled proteins were combined with four unlabeled optic tecta, which served as carrier. The tissue (30 to $40 \mathrm{mg}$ ) was homogenized in $5 \mathrm{ml}$ of TS buffer ( $1 \mathrm{~mm}$ triethanolamine (TEA), $\mathrm{pH} 7.4$, containing $0.32 \mathrm{M}$ sucrose). The supernatant of a $10-\mathrm{min}, 1000 \times g_{\text {av }}$ centrifugation $(3000 \mathrm{rpm}$ in a Sorvall SS-34 rotor, $\mathrm{RC} 2 \mathrm{~B}$ centrifuge) was re-centrifuged for $30 \mathrm{~min}$ at $100,000 \times \mathrm{g}_{\mathrm{av}}$ $(40,000 \mathrm{rpm}$ in a Beckman type 40 rotor, L5-65 ultracentrifuge). The resulting pellet, containing a crude membrane preparation, was re-homogenized in $2 \mathrm{ml}$ of TS buffer and layered over a discontinuous sucrose gradient (steps of $20,26,34,40$, and $55 \%(\mathrm{w} / \mathrm{v})$ sucrose in $1 \mathrm{~mm}$ TEA, pH 7.4). The gradient was centrifuged for $5 \mathrm{hr}$ at $1.5 \times 10^{5} \times g_{\text {av }}(35,000 \mathrm{rpm}$ in a Beckman SW-41 rotor). The material at each interface was collected with a Pasteur pipette and equal volumes of each fraction were assayed for the following enzymes which served as markers for the indicated membranes (Schimmel et al., 
1973): NADPH-dependent cytochrome $c$ reductase (endoplasmic reticulum), ouabain-sensitive $\left(\mathrm{Na}^{+}, \mathrm{K}^{+}\right)$-dependent adenosine triphosphatase (plasma membrane), and succinate-dependent cytochrome $c$ reductase (mitochondria).

Reaction mixtures for the cytochrome $c$ reductase assays (Sottocasa et al., 1967) contained $0.06 \mathrm{M} \mathrm{Na}_{2} \mathrm{HPO}_{4}$, $\mathrm{pH} 7.5,0.12 \mathrm{~mm} \mathrm{KCN}$, and the appropriate cofactor $(0.27$ mM NADPH or $0.03 \mathrm{~m}$ succinate). Twenty microliters of sample was added to $0.16 \mathrm{ml}$ of reaction mixture and 20 $\mu$ l of cytochrome $c(12 \mathrm{mg} / \mathrm{ml})$, and the change in optical density at $550 \mathrm{~nm}$ was determined spectrophotometrically at room temperature.

The ouabain-sensitive $\left(\mathrm{Na}^{+}, \mathrm{K}^{+}\right)$-dependent ATPase activity was determined as the difference in phosphate generated in the presence and absence of ouabain $\left(10^{-2}\right.$ M) when the sample was incubated with a solution containing imidazole $(50 \mathrm{~mm}), \mathrm{NaCl}(180 \mathrm{~mm}), \mathrm{KCl}(25 \mathrm{~mm})$, $\mathrm{NaN}_{3}(8 \mathrm{~mm})$, EGTA (ethylene glycol bis( $\beta$-aminoethyl ether)- $N, N, N^{\prime}, N^{\prime}$-tetra-acetic acid, $0.8 \mathrm{~mm}$ ), and $\mathrm{MgCl}_{2}$ ( $7 \mathrm{~mm}$ ), $\mathrm{pH} 7.4$, in a total volume of $50 \mu \mathrm{l}$ for $45 \mathrm{~min}$ at $37^{\circ} \mathrm{C}$ (Schimmel et al., 1973). The unusually high concentration of ouabain was necessary since the $\left(\mathrm{Na}^{+}, \mathrm{K}^{+}\right)$dependent ATPase of Bufo marinus is less sensitive to ouabain inhibition than the comparable enzyme from other species (Flier et al., 1979; J. S. Flier, Beth Israel Huspital, Boston, MA, personal communication). The reaction was terminated by the addition of perchloric acid $(10 \%)$ at $4^{\circ} \mathrm{C}$ and the supernatants of a 10 -min, 10,000-rpm centrifugation (Sorvall, RC2B centrifuge, SS34 rotor) were analyzed for phosphate by the method of Ames (1964).

In order to assay the transported proteins in the subcellular fractions, a sample of each fraction was precipitated in $7 \%$ trichloroacetic acid (TCA), washed with ether, and resuspended in an amount of denaturing buffer ( $2 \%$ sodium dodecyl sulfate (SDS), $2 \times 10^{-3} \mathrm{M}$ dithiothreitol, $0.01 \mathrm{M}$ Tris, $\mathrm{pH}$ 7.4) equal to one-tenth of the original volume of the fraction. The suspended samples were heated for $5 \mathrm{~min}$ at 90 to $100^{\circ} \mathrm{C}$, urea was added to a final concentration of $8 \mathrm{~m}(0.078 \mathrm{gm} / 100 \mu \mathrm{l})$, and $50 \mu \mathrm{l}$ of each sample was analyzed by one-dimensional SDS-ureapolyacrylamide gel electrophoresis (PAGE) (systems A and B of Skene and Willard, 1981b).

Solubility properties of the GAPs. Membrane fractions were washed sequentially with low salt EDTA (ethylenediaminetetra-acetate) and high salt essentially as described by Fairbanks et al. (1971). Fresh optic nerves containing labeled group I proteins (approximately $5 \mathrm{mg}$, wet weight, $100 \mu \mathrm{g}$ of protein) were homogenized in 200 $\mu \mathrm{l}$ of $\mathrm{H}$ buffer containing no EDTA (10 mM Tris, $\mathrm{pH} 7.4$, $1 \mathrm{~mm}$ dithiothreitol, $1 \mathrm{~mm}$ phenylmethylsulfonyl fluoride) and centrifuged at $100,000 \times g_{\text {av }}$ for $45 \mathrm{~min}$ at $4^{\circ} \mathrm{C}$. The resulting pellet was resuspended with a Pasteur pipette in $200 \mu \mathrm{l}$ of a solution containing $50 \mathrm{~mm}$ EDTA, $\mathrm{pH} 7.5$, heated $7 \mathrm{~min}$ at $37^{\circ} \mathrm{C}$, and centrifuged again at 100,000 $\times g_{a v}$ for $45 \mathrm{~min}$. The pellet of this centrifugation was resuspended in $200 \mu \mathrm{l}$ of a solution containing $\mathrm{NaCl}(0.5$ M) and Tris (10 mM, $\mathrm{pH} \mathrm{7.4)} \mathrm{at} \mathrm{room} \mathrm{temperature} \mathrm{and}$ again centrifuged $45 \mathrm{~min}$ at $100,000 \times \mathrm{g}_{\mathrm{av}}$. The supernatants of each centrifugation were brought to 7\% TCA by the addition of $100 \mu \mathrm{l}$ of $21 \%$ TCA and centrifuged $10 \mathrm{~min}$ at $3000 \times g_{\mathrm{av}}$, and the pellets were washed with diethyl ether. The pellet of the final $100,000 \times \mathrm{g}$ centrifugation and the TCA precipitates were resuspended in denaturing buffer and prepared for one-dimensional electrophoresis (system B of Skene and Willard, 1981b).

Two-dimensional electrophoresis \pm urea. Particulate fractions of labeled optic nerves were prepared for electrophoresis as previously described (Skene and Willard, 1981b), except that the denaturing solution contained $10 \%$ glycerol, and no urea was added. The samples were electrophoresed on slab gels $11 \mathrm{~cm}$ high containing $12 \%$ acrylamide, $0.36 \%$ bisacrylamide, $0.1 \%$ SDS, $0.06 \%$ TEMED ( $N, N, N^{\prime}, N^{\prime}$,-tetramethylethylenediamine), and $0.375 \mathrm{M}$ Tris, $\mathrm{pH} 8.9$, with a 4 -cm stacking gel containing $3 \%$ acrylamide, $0.09 \%$ bisacrylamide, $0.2 \%$ TEMED, and $0.25 \mathrm{M}$ Tris, $\mathrm{pH}$ 6.9. The Tris/glycine buffer system and other details were as described previously (Skene and Willard, 1981b). When the bromophenol tracking dye reached the bottom of the gel, the lanes containing labeled proteins were cut out and soaked for 10 to $15 \mathrm{~min}$ in an interdimensional transfer buffer containing $10 \mathrm{mM}$ Tris- $\mathrm{HCl}, 0.1 \%$ SDS, $10^{-4} \mathrm{M}$ dithiothreitol, and bromophenol blue as a tracking dye. The first dimension strips then were laid over the stacking gels of the second dimension gel (system B of Skene and Willard, 1981b). These second dimension gels were identical to the first dimension gels, except that they contained $8 \mathrm{M}$ urea throughout, and the running gel had a $\mathrm{pH}$ of 9.25. After electrophoresis in the second dimension, the gels were fixed, stained, and processed for fluorography as described previously (Skene and Willard, 1981b).

\section{Results}

Subcellular fractionation of GAPs. In mammalian retinal ganglion cells, group I axonally transported proteins are associated predominantly with an organelle(s) that has a similar buoyant density to the plasma membrane (Lorenz and Willard, 1978). Three GAPs (GAP-24, GAP-43, and GAP-50) axonally transported in group I of regenerating toad retinal ganglion cells sedimented at centrifugal forces of $100,000 \times g_{a v}$ (Skene and Willard, 1981b), indicating that they also are associated with some supramolecular structure. In order to determine the relative buoyant density of this structure, we subjected labeled group I proteins (taken $4 \mathrm{hr}$ after intraocular isotope injection) from control and regenerating nerves to centrifugation on sucrose density gradients and then compared the distribution of each growth-associated polypeptide across the gradient to the distribution of enzyme markers for the plasma membrane $\left(\left(\mathrm{Na}^{+}, \mathrm{K}^{+}\right)\right.$ATPase), endoplasmic reticulum (NADPH-dependent cytochrome $c$ reductase), and mitochondria (succinatedependent cytochrome $c$ reductase) (Fig. 1). All of the major group I polypeptides (e.g., polypeptides 6,11 , and 20; Skene and Willard, 1981a), including GAP-24, GAP. 43 , and GAP-50 in regenerating nerve samples, were distributed across the gradients in a pattern similar to that of the plasma membrane marker but clearly different from the markers for endoplasmic reticulum and mitochondrial membranes (Fig. 1). Therefore, the GAPs appear to be associated with an organelle with a density similar to the plasma membrane. 


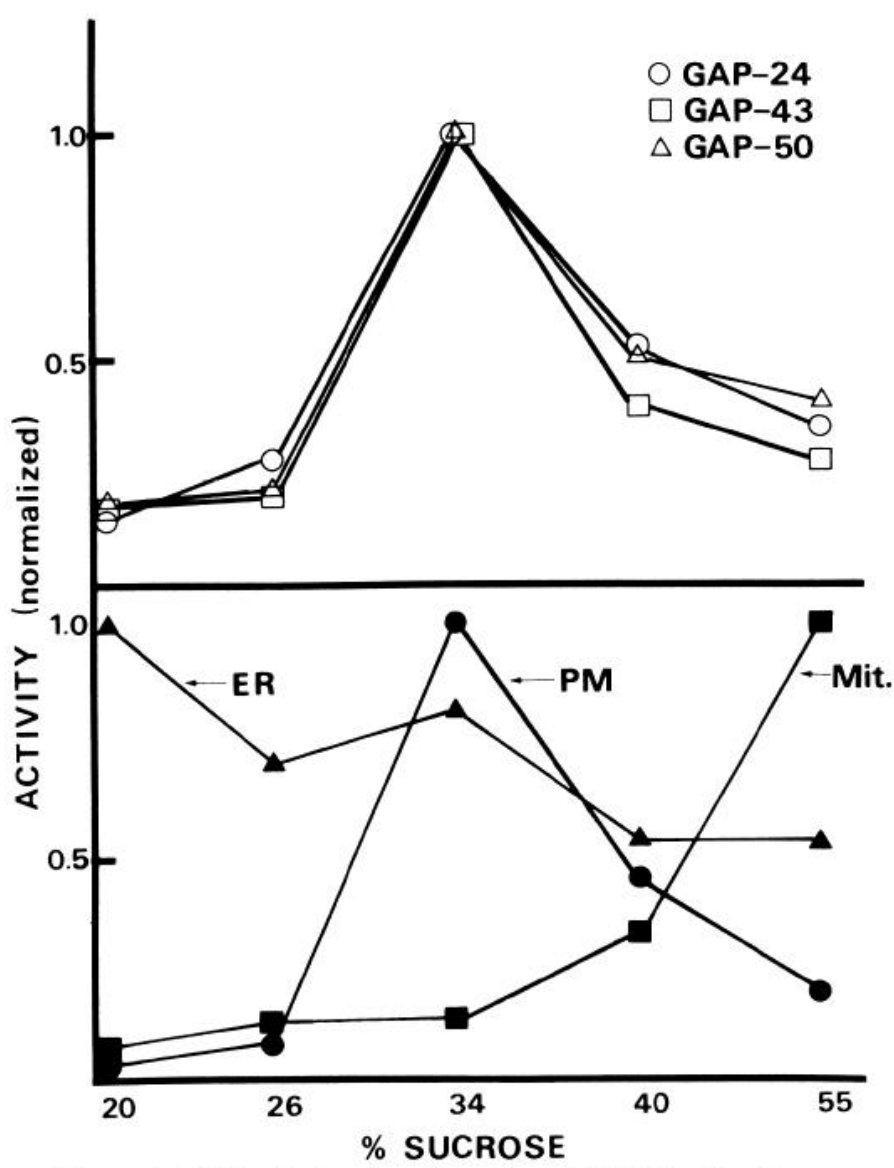

Figure 1. Subcellular fractionation of GAPs. Crude microsomal fractions were prepared from normal and regenerating (8 days post-axotomy) toad optic nerves containing $\left[{ }^{35} \mathrm{~S}\right] \mathrm{methi}-$ onine-labeled group I axonally transported proteins $(4 \mathrm{hr}$ after intraocular isotope injection) combined with unlabeled optic tecta which served as carrier. The fractions were centrifuged through a discontinuous sucrose density gradient containing the indicated steps of sucrose. The material which accumulated at each interface was collected and assayed for activities of marker enzymes for endoplasmic reticulum ( $E R$; NADPH-dependent cytochrome $c$ reductase), plasma membrane ( $P M$; $\left(\mathrm{Na}^{+}, \mathrm{K}^{+}\right)$-ATPase), and mitochondria (Mit.; succinate-dependent cytochrome $c$ reductase) and for total radioactivity. Samples of each fraction also were subjected to SDS-PAGE (systems A and B; Skene and Willard, 1981b) and fluorography; densitometry of the resulting fluorographs was used to determine the distribution of label associated with individual polypeptides. For each enzyme or polypeptide, the activity in each fraction was normalized to the fraction containing the highest activity. Unity is $110(E R), 130(P M)$, and 560 (Mit.) nmol/ min. All major group I polypeptides, as well as total group Iassociated radioactivity distributed across the sucrose gradient similarly to the GAPs. Their distribution was the same in normal and regenerating nerves.

Solubility properties of the GAPs. The preceding experiment suggested that GAP-24, GAP-43, and GAP-50 were associated with a membrane. If so, the GAPs could be either "peripheral proteins," associated with the surface of the membrane via electrostatic interaction, or "integral proteins," intimately associated with the lipid bilayer via hydrophobic interaction (Singer, 1974). The electrostatic interaction between peripheral proteins and membranes typically can be disrupted by removing divalent cations or by washing in high ionic strength solution (Fairbanks et al., 1971). We therefore homogenized and washed regenerating optic nerves containing labeled GAPs in either a low ionic strength medium containing a chelator of divalent cations (EDTA) or a high ionic strength medium $(0.5 \mathrm{M} \mathrm{NaCl})$ and determined the amount of each GAP which sedimented under a force of $100,000 \times g$ for $1 \mathrm{hr}$. Figure 2 shows that the major fraction of all three GAPs remained insoluble under these conditions. These results are consistent with the inter-

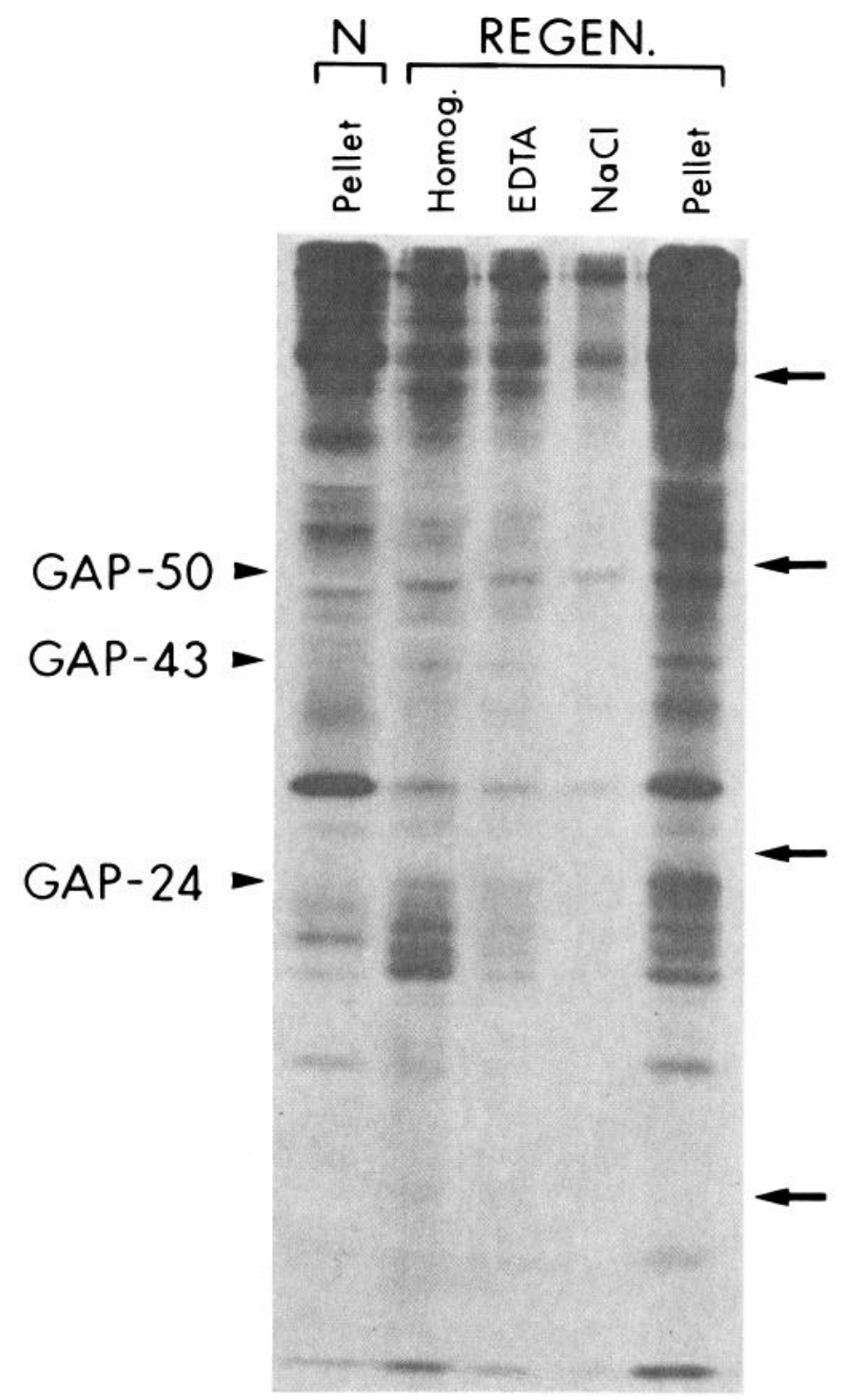

Figure 2. Extraction of regenerating (REGEN.) toad optic nerves with EDTA and $\mathrm{NaCl}(0.5 \mathrm{M})$. Group I proteins in regenerating toad optic nerves were labeled by intraocular injection of $\left[{ }^{35} \mathrm{~S}\right]$ methionine and recovered in the optic nerves $4 \mathrm{hr}$ after isotope injection. The labeled optic nerves were extracted sequentially with $\mathrm{H}$ buffer lacking EDTA (Homog.), $5 \mathrm{~mm}$ EDTA, and $0.5 \mathrm{~m} \mathrm{NaCl}$ as described under "Materials and Methods." The lanes show the labeled polypeptides in each of these extracts and the final pellet, as indicated. The final pellet from normal toad optic nerves $(N)$ processed similarly is shown for comparison. The arrows at right indicate molecular weights of $100,000,50,000,25,000$, and 15,000 . 
pretation that the GAPs are integral membrane proteins but do not exclude the possibility that they are intrinsically insoluble under the extraction conditions.

$G A P-50$ is a glycopeptide. Since the rapidly transported polypeptides in several systems have been shown to include the majority of transported glycoproteins (Bennett et al., 1973; Forman et al., 1972; Karlsson and Sjostrand, 1971) and since several authors have suggested a role for glycoproteins in directing axon growth (Barondes, 1976), we considered whether any of the polypeptides specifically induced during optic nerve regeneration might be glycoproteins. Consequently, we injected $\left[{ }^{3} \mathrm{H}\right]-$ fucose intraocularly to label retinal glycoproteins in control and regenerating toads, and $4 \mathrm{hr}$ later, recovered labeled group I proteins in the optic nerves. When we compared the fucose-labeled group I polypeptides from control and regenerating nerves by one-dimensional electrophoresis, a polypeptide co-migrating with GAP-50 was labeled in regenerating but not in control nerves (Fig. 3). When we compared the fucosylated group I polypeptides by means of two-dimensional electrophoretic analysis using non-equilibrium $\mathrm{pH}$ gradient gel electrophoresis (NEPHGE) as the first dimension (system D, Skene and Willard, 1981b), a closely spaced pair of fucosylated polypeptides resembling GAP-50 in both molecular weight and in their extremely rapid migration in NEPHGE also were labeled in regenerating, and not control, nerves (Fig. 4). Hence, we conclude that GAP-50 is fucosylated. No fucose-labeled polypeptides co-migrated with either GAP-24 or GAP-43 in either of these electrophoretic systems. Further, experiments in which various ${ }^{125} \mathrm{I}$-labeled plant lectins (i.e., succinyl concanavalin A, wheat germ agglutinin, and ricin) were bound to gels (Mintz and Glaser, 1978) containing optic nerve polypeptides showed no crush-sensitive labeling of polypeptides in the regions containing GAP-24 and GAP-43.

Unusual urea sensitivity of the electrophoretic mobility of GAP-24. We noted previously (Skene and Willard, 1981b) that electrophoretic resolution of GAP-24 requires urea and is affected by $\mathrm{pH}$. To determine whether these requirements reflect a specific effect of urea and high $\mathrm{pH}$ on the relative mobility of GAP-24 itself, we subjected labeled group I proteins from normal and regenerating toad optic nerves to SDS-PAGE in the absence of urea, at pH 8.9 (conditions which do not resolve GAP-24), then subjected the separated polypeptides to a second dimension of SDS-PAGE in the presence of urea at $\mathrm{pH} 9.25$ (Carmon et al., 1978). Since most polypeptides have similar relative mobilities in both dimensions, they form a diagonal line in the two-dimensional fluorograph (Fig. 5 ). The presence of urea at high $\mathrm{pH}$ affects the relative mobilities of only a few polypeptides, and they appear as spots above (or, in one case, below) this line. Since GAP24 is one of the small number of polypeptides which migrates substantially above the diagonal line (Fig. 5), some feature of its structure must render its electrophoretic mobility unusually sensitive to urea and high $\mathrm{pH}$. Since it migrates directly above other polypeptides in the line, it would be expected to co-migrate with them in the absence of urea, thus explaining the failure to resolve GAP-24 in the absence of urea.

Axonal distribution of labeled GAPs. In order to study

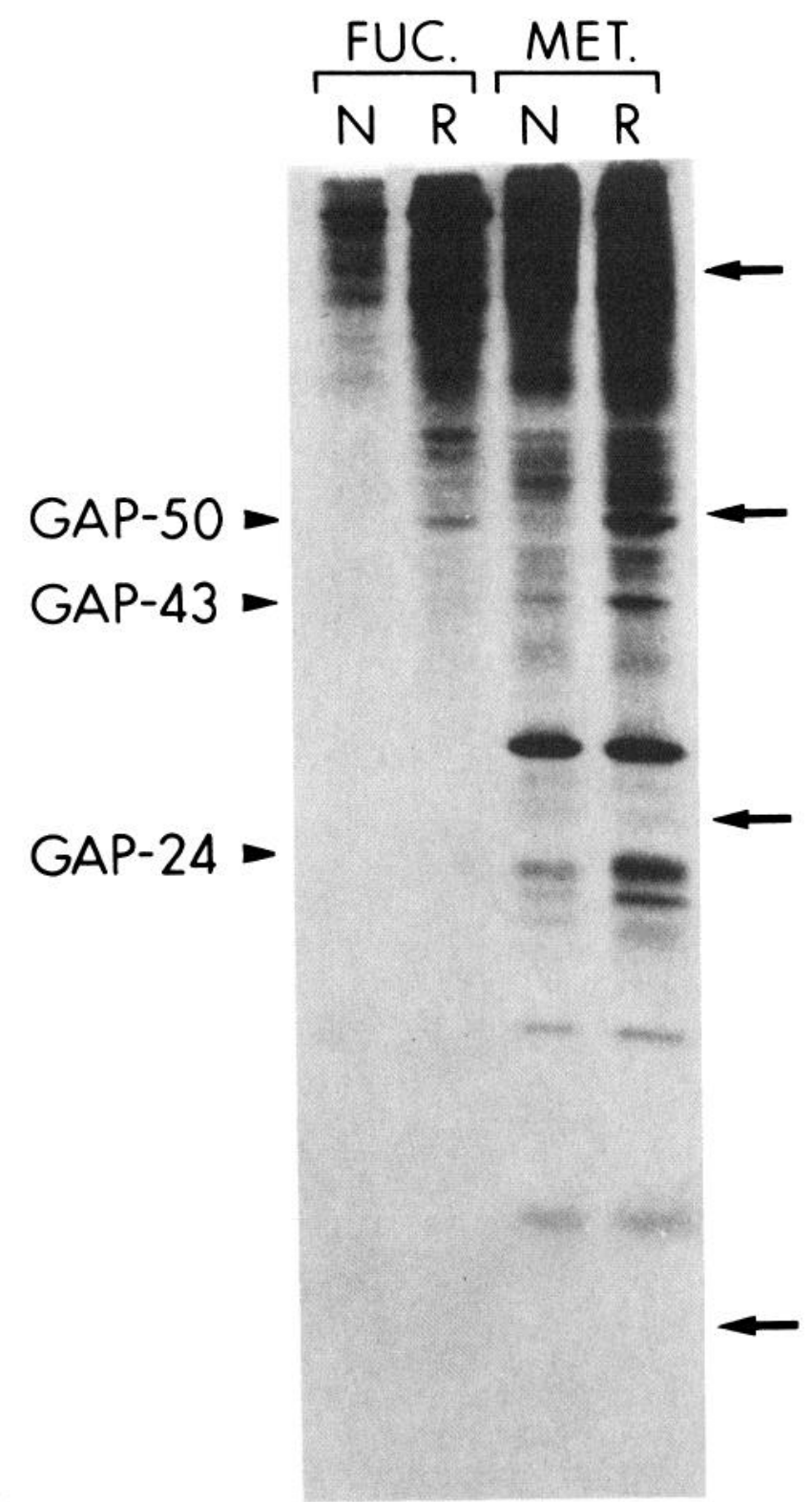

Figure 3. One-dimensional electrophoresis (system B; Skene and Willard, 1981b) of fucosylated group I axonally transported proteins in regenerating toad optic nerves. Group I proteins in normal $(N)$ and regenerating ( $R, 8$ days post-axotomy) toad optic nerves were labeled by intraocular injection of $\left[{ }^{3} \mathrm{H}\right]$ fucose (FUC.; $1.0 \mathrm{mCi})$ or $\left[{ }^{35} \mathrm{~S}\right]$ methionine $(M E T$.; $0.3 \mathrm{mCi})$ and recovered in the optic nerves $4 \mathrm{hr}$ after isotope injection. Particulate fractions of the labeled nerves were prepared and subjected to electrophoresis ( $12 \%$ polyacrylamide, $8 \mathrm{M}$ urea; system B of Skene and Willard, 1981b) and fluorography. GAP-24 is not resolved clearly under the conditions ( $\mathrm{pH} 8.9$ ) of electrophoresis employed here. The arrows at right indicate molecular weights of $100,000,50,000,25,000$, and 15,000 .

the distributions of labeled GAPs along the length of the axon, we crushed toad optic nerves and allowed 5 weeks for axons to regenerate. $\left.{ }^{35} \mathrm{~S}\right]$ Methionine then was injected into the eyes of the regenerating animals, and 12 $\mathrm{hr}$ later, the labeled axonally transported proteins in the combined optic nerve and optic tract and those in the optic tectum were analyzed separately. The ratio of trans- 


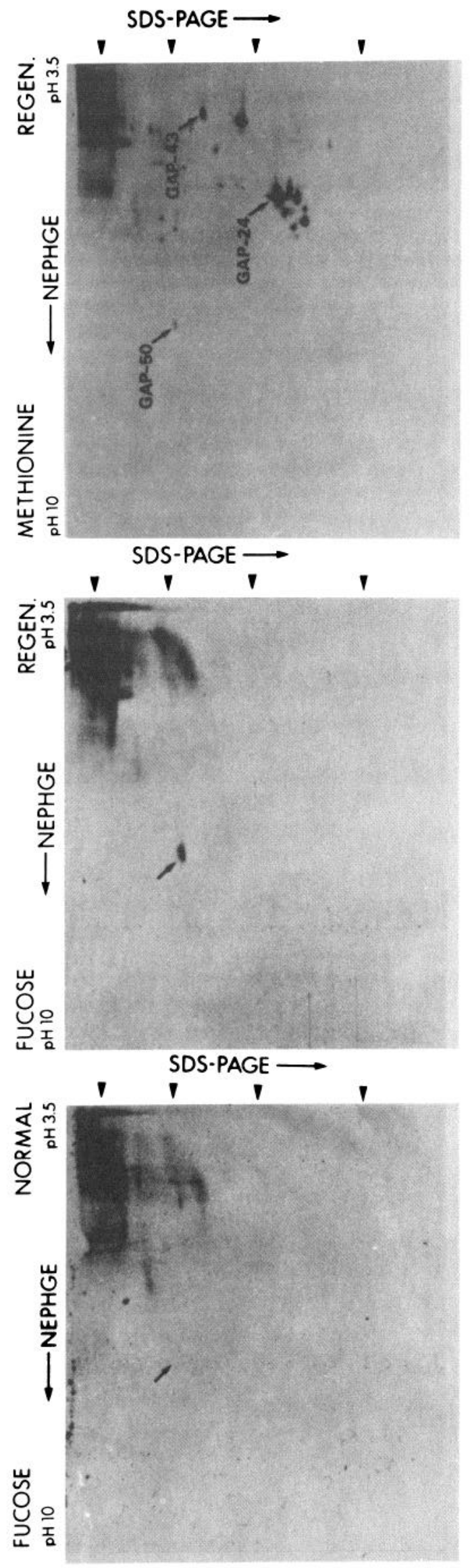

ported radioactivity in the tectum to that in the nerve and tract (0.8 to $1.2: 1)$ was about one-third of that expected for normal animals (3.0:1), suggesting that approximately two-thirds of the regenerating axon terminals had reached the optic tectum, while the remainder were still in the nerve and tract at this time (Table I; Skene, 1980). Thus, the tectum would be expected to be enriched (relative to the optic nerve-tract sample) for axon terminals as opposed to axon shafts. Table I summarizes the relative labeling of the three GAPs in these two tissue samples. Between 25 and $40 \%$ of the label associated with GAP-43 and GAP-50 accumulated in the tectum by $12 \mathrm{hr}$ after intraocular labeling; because the tectum accounts for less than $10 \%$ of the total axon length examined (Table I), this suggests that newly synthesized GAP-43 and GAP-50 accumulate preferentially in the terminal portions of axons. The distribution of GAP-24 between the tectum and the optic nerve-tract is clearly different from the distributions of the other GAPs, and it is consistent with a more uniform distribution of GAP24 along the axons (Table I).

Disappearance of label from the GAPs. In an effort to estimate the rate at which newly synthesized GAPs turn over in regenerating axons, we labeled the retinae of toads which had been allowed to regenerate for either 8 days or 5 weeks after axotomy and estimated the amount of label in each GAP at various times after labeling $(4,6$, 12,24 , and $48 \mathrm{hr}$ ) by means of one- or two-dimensional electrophoresis and densitometric scanning of the resulting fluorographs (Fig. 6). The GAP-associated label in the combined optic nerve and optic tract disappeared rapidly with similar time courses early (8 days) or late (5 weeks) in regeneration. Label associated with GAP-24 began to decline $6 \mathrm{hr}$ after the isotope injection, was half of the $6-\mathrm{hr}$ value by $12 \mathrm{hr}$, and could not be detected 24 $\mathrm{hr}$ or more after the injection. Since radioactive precursor may be available for incorporation into retinal protein for several hours after the isotope injection, GAP-24 appears to decay with a maximum half-time of 4 to $6 \mathrm{hr}$. GAP-43- and GAP-50-associated label disappeared significantly more slowly. GAP-50-associated label appeared to have a maximum half-time of approximately 1 day (although the low degree of maximum labeling of GAP-50 limited the accuracy of this estimate), while label associated with GAP-43 declined with a half-time of 2 to 3 days. In toads injected 5 weeks after axotomy, the disappearance of labeled GAP-43 and GAP-50 from

Figure 4. Two-dimensional (NEPHGE-PAGE) electrophoresis (system D of Skene and Willard, 1981b) of fucosylated group I proteins. Regenerating (REGEN.) toad optic nerves were labeled by intraocular injection of $\left[{ }^{3} \mathrm{H}\right] \mathrm{fucose}$, and the labeled proteins were recovered in the optic nerve $4 \mathrm{hr}$ after isotope injection. Particulate fractions of the labeled nerves were subjected to two-dimensional electrophoresis (system D) and fluorography. The first dimension is NEPHGE, with the origin at right; the second dimension is SDS-PAGE (12\% polyacrylamide, $8 \mathrm{M}$ urea; system B of Skene and Willard, 1981b). A comparable fluorograph of $\left[{ }^{35} \mathrm{~S}\right]$ methionine-labeled proteins from a regenerating toad optic nerve is included for comparison. The arrowheads at right indicate molecular weights of 100,000, $50,000,25,000$, and 15,000 . 

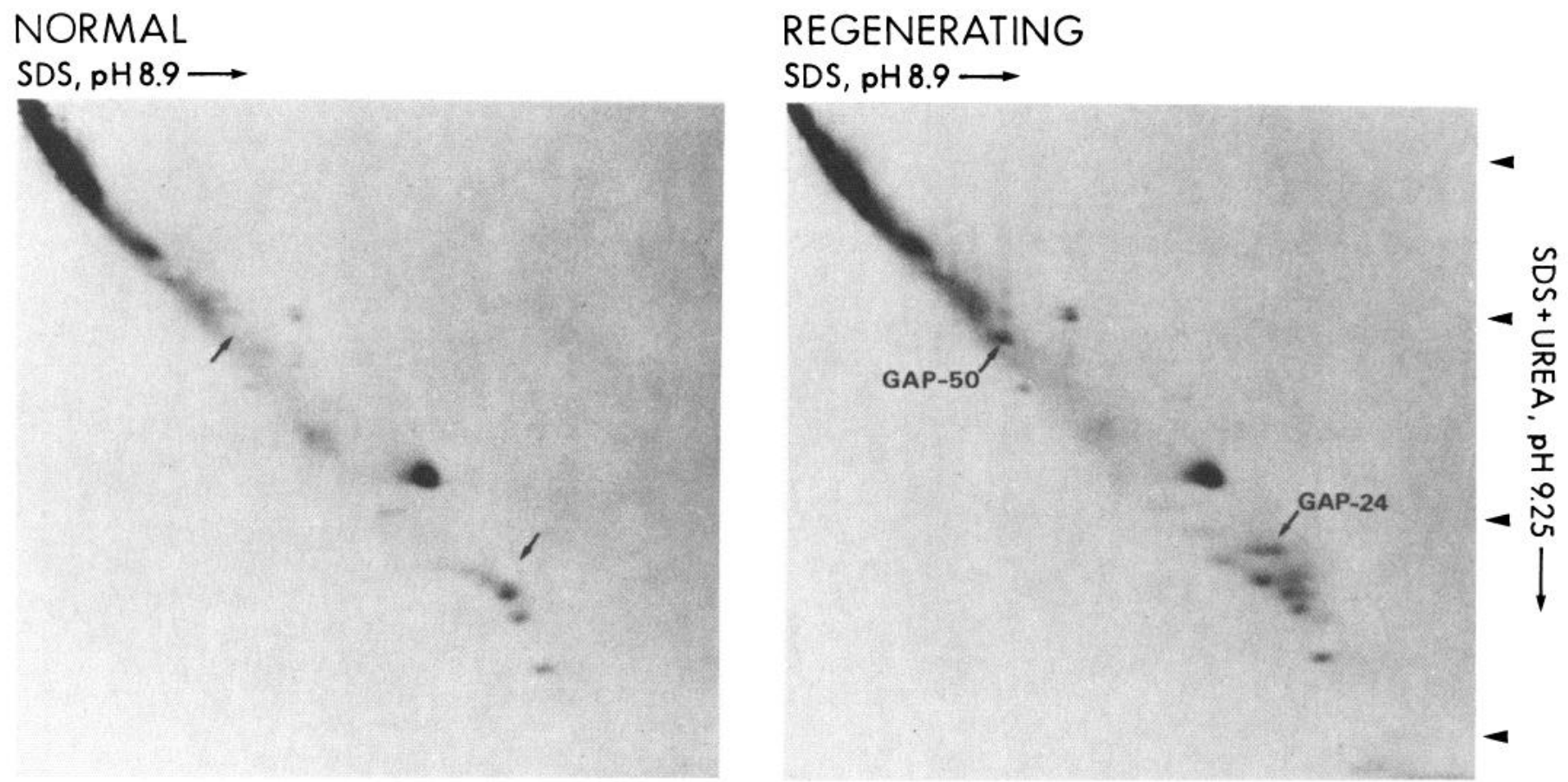

Figure 5. Effect of urea and high $\mathrm{pH}$ on the relative mobility of GAP-24 in SDS-PAGE. [ ${ }^{35}$ S]Methionine-labeled group I axonally transported proteins from normal and regenerating (8 days post-axotomy) toad optic nerves were subjected to SDSPAGE in the absence (horizontal dimension, origin at left) and presence (second dimension) of $8 \mathrm{~m}$ urea. The pH in the first dimension was 8.9 ; the $\mathrm{pH}$ in the second dimension was 9.25 (see "Materials and Methods"). The labeled polypeptides were visualized by fluorography.

TABLE I

Fraction of GAP-associated label localized in tectum

\begin{tabular}{lcccccc}
\hline & \multicolumn{3}{c}{ Observed } & & \multicolumn{2}{c}{ Expected } \\
\cline { 2 - 4 } \cline { 6 - 7 } & GAP-50 & GAP-43 & GAP-24 & & Tip-associated $^{a}$ & Uniform $^{b}$ \\
\hline Toad 1 & 0.32 & 0.32 & 0.04 & & 0.72 & $\leq 0.09$ \\
Toad 2 & 0.42 & 0.23 & 0.02 & & 0.59 & $\leq 0.07$ \\
& & & & & 0.64 & $\leq 0.08$ \\
\hline
\end{tabular}

${ }^{a}$ The fraction of axon tips which had reached the optic tectum after 5 weeks of regeneration, assuming that the fraction of radioactivity that accumulates in the tips after $12 \mathrm{hr}$ of transport is the same as in normal toads. If a larger than normal fraction of transported proteins accumulates in the tip of regenerating axons, the expected value would be less, with a lower limit of 0.49 for the mean.

${ }^{b}$ The maximum fraction of total axon length which could be in the tectum, assuming that 0.72 and 0.59 of the axons had fully innervated the tectum in the respective toads. These results are estimated from the mean length of normal axons in the tectum (half-width of the tectum) as a fraction of total length of the optic nerve-optic tract-optic tectum (Skene and Willard, 1981a). The interpretation of this experiment is considered in greater detail in Skene, 1980.

the tectum (in which regenerating axons already may have established synapses (Skene and Willard, 1981b)) resembled their respective time courses in the combined nerve and tract (which probably contained numerous growing tips as well as axon shafts).

\section{Discussion}

We have reported here several characteristics of three rapidly transported polypeptides (GAPs) whose relative degree of labeling increases markedly following axotomy of toad optic nerves. We consider now the possible relationship of these characteristics to the model (Skene and Willard, 1981b) that the GAPs mediate essential growthrelated functions and that their induction is a key event in allowing a mature neuron to enter a growth state.

All three of the GAPs studied here appear to be associated with membranous organelles similar in density to the plasma membrane, and their solubility properties suggest that they may be integral membrane proteins. Despite their apparent intimate association with membranes, all three of these GAPs must contain a significant number of polar amino acids, since they migrate rapidly under the influence of their native charge into NEPHGE gels. (The relative proportions of acidic and basic amino acid varies among the three polypeptides since they are isoelectric at acidic (GAP-43), basic (GAP-50), or neutral (GAP-24) $\mathrm{pH}$ values (Skene and Willard, 1981b).) The considerable polarity of the GAPs suggests that significant portions of each of these proteins must extend away from the lipid bilayer of the membrane. In this regard, it is interesting to consider that if a GAP were associated with the plasma membrane itself, a disposition on the external surface of the membrane could put it in a position to mediate interactions between the growing axon and its local environment. This conjecture is especially plausible in the case of GAP-50 which is a fucosylated glycopeptide; the sugar moieties of plasma membrane glycoproteins typically project from the external surface of the cell (Nicolson, 1974; Rambourg, 1971; Winzler, 1970). A GAP projecting from the internal surface of the plasma membrane could be in a position to mediate 


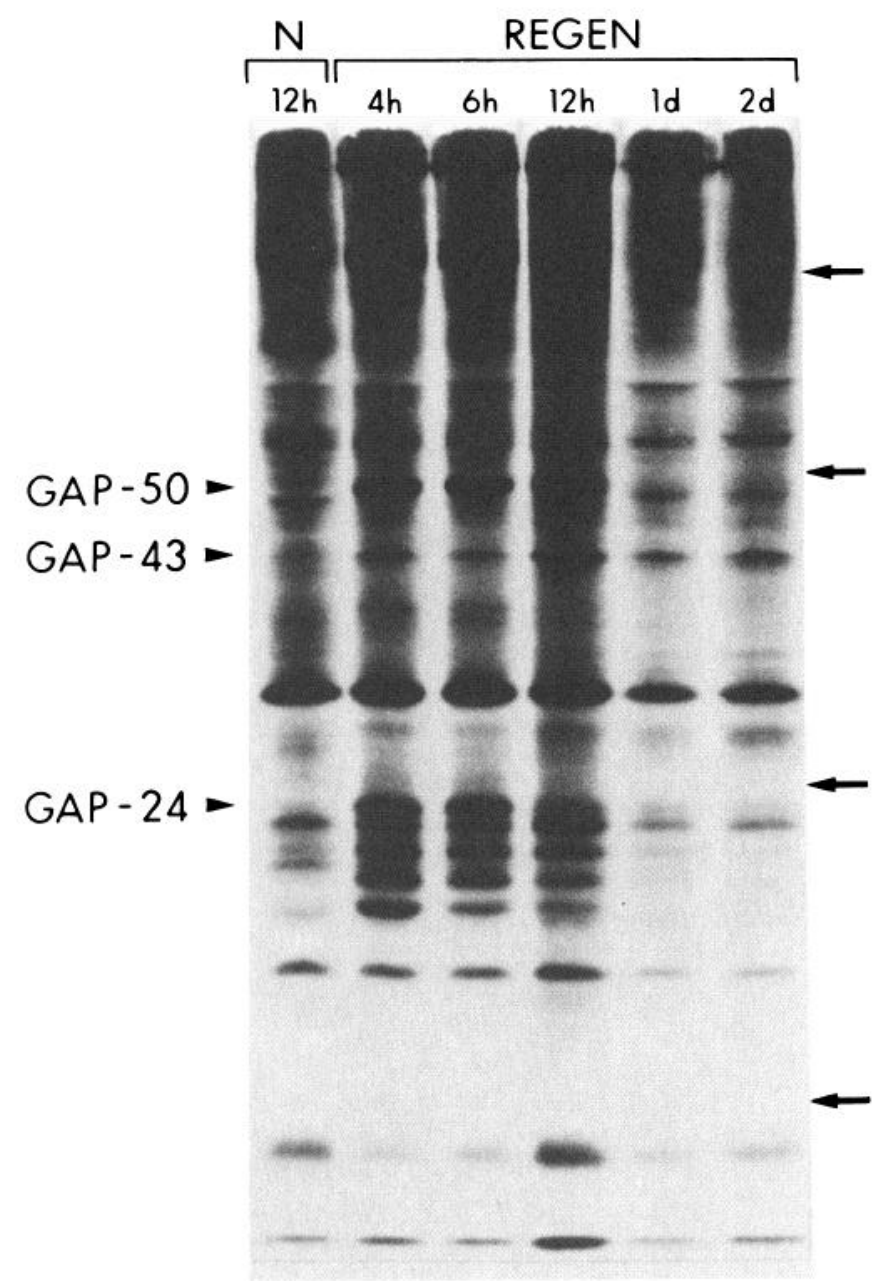

Figure 6. Time course of disappearance of labeled GAPs from regenerating toad optic nerves. Eight days after the optic nerve was crushed, $\left[{ }^{35} \mathrm{~S}\right]$ methionine $(0.3 \mathrm{mCi})$ was injected into the posterior eye chambers of toads; at the indicated times after isotope injection, the optic nerves were removed. Particulate fractions from the labeled nerves were analyzed by one-dimensional electrophoresis ( $12 \%$ polyacrylamide, $8 \mathrm{~m}$ urea; system B of Skene and Willard, 1981b) and fluorography. The arrows at right indicate molecular weights of $100,000,50,000,25,000$, and $15,000 . N$, normal toad optic nerves; $R E G E N$, regenerating toad optic nerves.

interactions between the membrane and axoplasmic elements including the cytoskeleton. Alternatively, it must be considered that GAPs might be associated with some internal membranous organelle of similar buoyant density to the plasma membrane. One such alternative organelle might be the dense core vesicles reported to be a unique feature of regenerating axons in goldfish (Murray, 1976), newts (Lentz, 1967), and toads (Reier and Webster, 1974).

In spite of the similarities among the three GAPs in their solubility properties and their behavior on sucrose density gradients, certain considerations suggest that they are involved in separate functions. The apparent concentration of label associated with GAP-50 and GAP43 in the terminal portions of the axons is consistent with the possibility that these polypeptides are involved in tip-specific functions (e.g., mediating interactions between the growth cone and its environment or directing filopodial movements). On the other hand, the distribution of label associated with GAP-24 could be interpreted to indicate that it performs a growth-related function along the length of the axon. Owing to the complexity of the experimental system, these inferences of the specific destinations for the GAPs from the spatial distribution of their associated label are not conclusive (a detailed discussion of the limitations in interpreting these experiments is given in Skene, 1980); however, the differential distribution of GAP-associated label does suggest functional differences between GAP-24 and the other GAPs.

The three GAPs also differ in their apparent rates of turnover in regenerating axons. Labeled GAP-24 disappears very rapidly $\left(t_{1 / 2} \sim 4\right.$ to $6 \mathrm{hr}$ ), labeled GAP-50 disappears at an intermediate rate $\left(t_{1 / 2} \sim 1\right.$ day $)$, and GAP-43 label declines more slowly $\left(t_{1 / 2}>2\right.$ days). The determination of the rate of disappearance of the labeled GAPs from the retinal ganglion cell provides only a minimum estimate of the actual rate of their turnover, since the degree to which the labeled proteins might continue to be supplied to the axon from labeled pools in the cell bodies is unknown. However, it is clear from the rapid disappearance of label from GAP-24 that this protein has a very short lifetime in the axons. Such rapid transport and rapid turnover could allow the function mediated by GAP-24 to be regulated sensitively temporally (Willard et al., 1974). For example, if GAP-24 mediated some aspect of axon sprouting, its rapid turnover and transport could allow sprouting to be terminated within a few hours of the establishment of a synaptic contact simply by terminating its synthesis in the cell body.

A unique property of GAP-24 is the specific retardation of its electrophoretic mobility at high $\mathrm{pH}$ in the presence of $8 \mathrm{~m}$ urea. This feature of GAP-24 is sufficiently unusual that it should be useful as one criterion for identifying structurally related proteins in other systems since the effect presumably represents an uncommon feature of the structure of GAP-24 (Skene and Willard, 1981c). Since SDS denaturation induces a condensed rod-like configuration in proteins, while urea induces an open, random coil, it could be imagined that GAP-24 possesses an unusual number of some amino acids (or configuration of amino acids) which favors the binding of an unusually high ratio of urea to SDS causing GAP-24 to migrate unusually slowly on urea-SDS-PAGE (Skene, 1980).

\section{References}

Ames, B. N. (1964) Assay of inorganic phosphate, total phosphate, and phosphatases. Methods Enzymol. 8: 115-118.

Barondes, S. H., ed. (1976) Neuronal Recognition, Plenum Press, New York.

Bennett, G., L. di Giamberardino, H. L. Koenig, and B. Droz (1973) Axonal migration of protein and glycoprotein to nerve endings. II. Radioautographic analysis of the renewal of glycoproteins in nerve endings of chicken ciliary ganglion after intracerebral injection of $\left[{ }^{3} \mathrm{H}\right]$-fucose and $\left[{ }^{3} \mathrm{H}\right]$-glucosamine. Brain Res. 60: 129-146.

Carmon, Y., S. Neuman, and D. Yaffe (1978) Synthesis of tropomyosin in myogenic cultures and in RNA-directed cell- 
free systems: Qualitative changes in the polypeptides. Cell 14: 393-401.

Fairbanks, G., T. L. Steck, and D. F. H. Wallach (1971) Electrophoretic analysis of the major polypeptides of human erythrocyte membrane. Biochemistry 10: 2606-2617.

Flier, J. S., E. Maratos-Flier, J. A. Pallotta, and D. McIsaac (1979) Endogenous digitalis-like activity in the plasma of the toad Bufo marinus. Nature 279: 341-343.

Forman, D. S., B. Grafstein, and B. S. McEwen (1972) Rapid axonal transport of $\left[{ }^{3} \mathrm{H}\right]$-fucosyl glycoproteins in the goldfish optic system. Brain Res. 48: 327-342.

Karlsson, J. -O., and J. Sjostrand (1971) Rapid intracellular transport of fucose-containing glycoproteins in retinal ganglion cells. J. Neurochem. 18: 2209-2216.

Lentz, T. L. (1967) Fine structure of nerves in the regenerating limb of the newt Triturus. Am. J. Anat. 121: 647-670.

Lorenz, T., and M. Willard (1978) Subcellular fractionation of intra-axonally transported polypeptides in the rabbit visual system. Proc. Natl. Acad. Sci. U. S. A. 75: 505-509.

Mintz, G., and L. Glaser (1978) Specific glycoprotein changes during development of the chick neural retina. J. Cell Biol. 79: $132-137$.

Murray, M. (1976) Regeneration of retinal axons into the goldfish optic tectum. J. Comp. Neurol. 168: 175-196.

Nicolson, G. L. (1974) The interaction of lectins with animal cell surfaces. Int. Rev. Cytol. 39: 89-190.

Rambourg, A. (1971) Morphological and histochemical aspects of glycoproteins at the surface of animal cells. Int. Rev. Cytol. 31: 57-114.

Reier, P. J., and H. deF. Webster (1974) Regeneration and remyelination of Xenopus tadpole optic nerve fibres following transection or crush. J. Neurocytol. 3: 591-618.

Schimmel, S. D., C. Kent, R. Bischoff, and P. R. Vagelos (1973) Plasma membrane from cultured muscle cells: Isolation procedure and separation of putative plasma-membrane marker enzymes. Proc. Natl. Acad. Sci. U. S. A. 70: 3195-3199.

Singer, S. J. (1974) The molecular organization of membranes. Annu. Rev. Biochem. 43: 805-833.

Skene, J. H. P. (1980) The GAP hypothesis-Axonally transported proteins associated with axon growth. Ph.D. thesis, Washington University, St. Louis.

Skene, J. H. P., and M. Willard (1981a) Electrophoretic analysis of axonally transported proteins in toad retinal ganglion cells. J. Neurochem., in press.

Skene, J. H. P., and M. Willard (1981b) Changes in axonally transported proteins during axon regeneration in toad retinal ganglion cells. J. Cell Biol. 89: 86-95.

Skene, J. H. P., and M. Willard (1981c) Axonally transported proteins associated with axon growth in rabbit central and peripheral nervous systems. J. Cell Biol. 89: 96-103.

Sottocasa, G. L., B. Kuylenstierna, L. Ernster, and A. Bergstrand (1967) An electron-transport system associated with the outer membrane of liver mitochondria. J. Cell Biol. 32: 415-438.

Willard, M. B., W. M. Cowan, and P. R. Vagelos (1974) The polypeptide composition of intra-axonally transported proteins: Evidence for four transport velocities. Proc. Natl. Acad. Sci. U. S. A. 71: 2183-2187.

Winzler, R. J. (1970) Carbohydrates in cell surfaces. Int. Rev. Cytol. 29: 77-125. 